\title{
Flood Preparedness of Selected Elementary Schools in Zamboanga del Sur and Zamboanga Sibugay, Philippines
}

\author{
Ruth C. Reyes, Victoria O. Sumanpan \\ aruthbcapayas@gmail.com,vos123@yahoo.com \\ University of Science and Technology of Southern Philippines, Cagayan de Oro City, Philippines \\ Malangas Central Sped Center, Malangas, 7038, Zamboanga Sibugay, Philippines
}

\begin{abstract}
Preparedness is an integral component of any organization to thrive in a disaster-prone setting. This study aimed to appraise flood preparedness of eight (8) selected schools of Zamboanga del Sur and Zamboanga Sibugay that uses quantitative-qualitative method. Purposive sampling was used for teachers and Local Disaster Risk Reduction Evaluators, and random sampling for grade six (6) pupils. Researcher-made questionnaires were administered which were subjected to content validity and reliability tests.

Seven schools rated "Good" in disaster-preparedness activities namely: Disaster Risk Reduction Group, Preparation of Disaster Risk Reduction Plan, and Disaster Risk Reduction Measure. The 76.7\% of teachers were "Very Capable" in Flood Preparedness Mitigation, 86\%, and 80.2\% were "Very Capable" in Flood Response, and Flood Rehabilitation, respectively. The level of capability was due to proper dissemination, advocacy, and campaign among Local Disaster Risk Reduction Evaluators. Furthermore, $28.4 \%$ of pupils were "Fully Informed", and $36.9 \%$ were "Almost Fully Informed" about the flood in their schools. Capacitating teachers, pupils, and other external stakeholders should be continued, and close coordination with Local Disaster Risk Reduction Evaluators should be sustained since the flood-control mechanism can be managed when everyone is engaged in disaster-preparedness activities.
\end{abstract}

Keywords: disaster; flood preparedness; zamboanga del sur; zamboanga sibugay

Published by IJRP.ORG. Selection and/or peer-review under responsibility of International Journal of Research Publications (IJRP.ORG) 


\section{INTRODUCTION}

The onslaught of typhoons, cyclones, or hurricanes across the world has made human lives vulnerable to hazards. Climate change strongly contributes to the abnormalities of these typhoons causing natural disasters and emergencies.

The Philippines is already on the west coast of the world's largest body of water, with its more volatile storm oceans on Earth, making it very vulnerable to typhoon-like disasters. Thus, disaster preparedness and risk reduction have to be institutionalized, implemented, and monitored, and that awareness campaign has to be the primordial duty of all government and non-government organizations.

Meanwhile, preparedness has to be always part of human-daily lives. Preparedness has been one of the priorities of local and national governments to be effective in the face of catastrophic events. One major local disaster that has devastated and put human lives at risk is flooding.

According to the United Nations Office for Disaster Risk Reduction [(UNISDR) 2015)], although storm is considered to be among the most devastating weather-related catastrophe, 47 percent of all climate events caused by the rest of Asian people affected by flood events were recorded. Emergency Events Database (EMDAT) of Centre for Research for Epidemiology of Disasters (CRED) has recorded several cases of flood as natural hazards from 2005 to 2017 and has increased from 127 to 172 due to storm followed by earthquakes.

One prevalent example of a disaster that makes schools at risk is flooding. In the Second District of Zamboanga del Sur and First District of Zamboanga Sibugay, major rivers such as Bayog river and Sibuguey river are catch basins, especially during heavy rains. When the typhoon Vinta struck the Zamboanga Peninsula area during December 23, 2017, it destroyed property and killed lives.The first typhoon that ravaged the five towns and three provinces of Region 9 was Vinta, with high casualty count and property damage.Floodwaters reached the school buildings and destroyed the school's properties. Luckily, no learners and personnel were affected by the storm because it happened during Christmas vacation.

In recent years, the Divisions of Zamboanga del Sur and Zamboanga Sibugay have been experiencing floods because some schools are built near creeks, riverbanks, and other water bodies consequently, these schools experience flooding even without typhoons, so long as there is heavy rain brought by the monsoon.

Subsequently, the Department of Education developed Disaster Risk Reduction Resource Manual to protect the lives of every individual in the school and the school properties through DepEd. Order No. 55,s. 2007. Stipulated in the manual is the implementation of monitoring and evaluation for every school in all DRRMrelated programs and projects.

DepEd Order No. 21s. 2015, otherwise known as Disaster Risk Reduction and Management Coordination and Information Protocol started the institutionalization of protocols, roles, and responsibilities of individuals and offices to fast track correspondences. Possible misunderstanding may be avoided as to who, where, and how to conduct particular tasks relating to climate change mitigation and adaptation. The establishment of DRRM Coordinators could help facilitate the processes involving risk reduction and management.

Besides, the safety of the lives of the school administrators, teachers, and learners, and the assurance that the delivery of education would continue and be prioritized even during time of disaster had motivated this 
researcher to conduct this study particularly among the eight selected elementary schools in Zamboanga del Sur and Zamboanga Sibugay, which the Local Disaster Risk Mitigation and Management officers established as potential zones of flooding. Given that disasters can be natural or man-made that could disrupt schools and nearby communities, the researcher wanted to delimit the disaster types to flooding since the abovementioned eight selected school are situated in an area that is highly susceptible to flooding.

The investigator also wanted to assess whether in the stated DepEd Order No. 55, s. 2007, the planning and implementation related to Disaster Risk Reduction and Management in the study's chosen schools had been introduced, thus underscoring preparedness as one of the priorities of school administrators and teachers to maintain safety among learners and the school properties.

\section{Statement of the Problem.}

The main goal of this research was to determine the extent of execution of flood disaster preparedness at the selected schools in Zamboanga del Sur and Zamboanga Sibugay. Specifically, the study aimed to address the following questions:

1. What is the level of implementation of the selected schools of Zamboanga del Sur and Zamboanga Sibugay to the following?

1.1. Organization of School Disaster Risk Reduction Group (SDRRG);

1.2. Preparation of Disaster Risk Reduction Plan (DRRP) and;

1.3. Implementation of Disaster Risk Reduction Measures (DRRM)?

2. What is the level of capability of teachers of the selected schools of the two provinces in terms of:

1.1. Flood Preparedness and Mitigation

2.2. Flood Response and;

2.3. Flood Rehabilitation?

3. What is the level of the selected schools of Zamboanga del Sur and Zamboanga Sibugay in terms of:

4.1. Orientation of pupils about a flood in their school and;

4.2. Availability of facilities and equipment/materials related to disaster risk reduction?

\section{REVIEW OF RELATED LITERATURE AND STUDIES}

\section{Legal Bases}

Management of Disaster Risk Reduction occurred even before RA 10121 was implemented. It is mentioned and defined that DRRM is to be incorporated by DepEd, CHED, TESDA and other relevant stakeholders into school curricula at both secondary school level of curriculum. Through the Republic Act 10121 or the Philippine Disaster Risk Reduction and Management System, the government declares that the state's intention is to protect the fundamental rights and property of citizens by coping with the underlying causes of disaster susceptibility, by improving the institutional capacity for disaster risk reduction and management, and by boosting the institutional capacity for disaster prevention and mitigation.

Via DepEd Order No. 55, s.2007, the Department of Education prioritizes the integration of Disaster Risk Reduction Management into the educational system and the introduction of relevant planning and implementation. Its aim is to systematically establish and apply policies, programs and policies in the broad sense of environmental sustainability to mitigate the risk of vulnerabilities and the occurrence of impacts of climate change in society. The following are Safe School Activities in relation to disaster risk mitigation initiatives through non-structural frameworks pursuant to paragraph three (3)(a.) mainstreaming Disaster Risk Reduction Concepts in Elementary and Secondary School, (b.) school mapping exercise, (c.) 
schools water and electricity facilities assessment project (d.) preparation of disaster preparedness modules through multi-media; and, (e.) Conduct of earthquake and fire simulations on a monthly basis; and (f.) road safety education for children. The 6 sub-components served as a guide and life-preserving factors to any school at times of disaster.

\section{Disaster Risk Reduction in International Community}

The Hyogo Framework for Action (HFA) 2005-2015 is the main tool embraced by the Philippines as one of the participant countries of the United Nations towards the implementation of disaster risk reduction, in order to create sustainability for nations and communities by reducing catastrophe casualties around 2015.The framework has five focus areas for action aimed at achieving disaster mitigation for sustainable development. "Make disaster risk reduction a priority" is the very first area of concern. It encourages every member-state should make disaster risk reduction a national concern of the government at all levels in order to build resilience among individuals for sustainable development of the country ( Hyogoframework, 2005). The second goal of the HFA is to understand the consequences and take appropriate steps. By improving early warning, the value of recognizing, evaluating and tracking disaster risk are ways to minimize the effect of catastrophe on private individuals' lives, livelihoods and assets. Priority 3 is "Build Understanding and Awareness". It is in this priority that proper information dissemination; advocacy and campaign are instruments that can elevate the stage of understanding and awareness about every individual particularly on localized disaster. To reduce risk is the fourth area of priority. There are certain measures that should be done to lessen the risk of disaster by constructing flood control infrastructure, elevating the floor of a flood prone building, reconstruction and retrofitting of the building so that it can withstand with the disaster. The fourth priority is to "be prepared and ready to act". The national, regional and local levels of the government are required to be prepared and to respond effectively at all times for a disaster (UNISDR, 2005). In this connection, every learner who comes to school to acquire knowledge and skills in academics must also acquire understanding and awareness about disaster for the safety of their lives. In addition, in order to improve the safety and health of the workplace and its readiness, the school will therefore be committed to building understanding and knowledge among students through disaster risk mitigation training and workshops. Additionally, aside from an avenue of education, the school itself is necessary to be a disaster prepared institution. Safety measures and precautions must be taken by schools to mitigate the impact of any hazard that might affect the institution particularly the learners and the education workers that would result to a disastrous event.

\section{Disaster Risk Reduction in Education Sector}

At a time when the frequency and intensity of extreme climatic events are increasing, more and more school-going children in the world were widely affected by disasters, fires, flooding, hurricanes, mudslides as well as other environmental events. In addition, these events have a traumatic impact on human life, mostly on the health of pupils, the education system and student learning programs.

Comprehensive School Safety has three pillars. Pillar 1 is Safe Learning Facilities. This first pillar entails education and planning authorities who are decision makers to select safe school site, design, construct and maintain the schools to make learning environment and facilities safe for the learners and education workers. The second pillar, School Disaster Management, encourages academic program officials in each state to cooperate with local disaster management leaders in the national and regional education government and private education leaders. Likewise, in the school level, the staff, students and parents must also be involved in maintaining safe learning environments by assessing and reduction of systemic, nonstructural, institutional, environmental and economic threats and by building capacity for intervention and preparation for sustainability of learning. Risk Reduction and Resilience Education is the third pillar that 
encourages curriculum and educational materials developer, faculty of pedagogic institutes, teacher trainers, teacher, student groups, participants of activities and learners work to build and reinforce a secure environment, sustainability and community stability (GADRRRES, 2017). The Ambitious School Safety strategy as a whole has been aimed at reducing the impacts of any and all threats to the education industry.

\section{Foreign Studies}

The Bureau of Fire and Safety and Local Disaster Risk Reduction Management Office's periodic disaster and fire drilling programs for schools endorse the principle of Kuntz et al. This concept is also confirmed by Mills et al., 2014, that catastrophe scenarios enable learners to reflect rapidly on their feet and pass abilities gained (Mills et al., 2014).

Even if this was not how they thought, principals and teachers should show calmness and trust mostly during case of a catastrophe. Schools should concentrate with the well of students, teachers and families and on putting children integrated through healthy learning habits while reducing persistent distress (Education Review Office, 2013).

On the other hand, Boon (2014) which stressed that school disaster education is essential to raise awareness among learners and their communities and to encourage preparedness action. Lack of knowledge about disasters among the people and lack of provision of mitigation measures could be a reason for millions of people and millions of dollars' worth of damage to properties and Lots of people die and many are homeless, and this also has a detrimental impact mostly on country's social development.

In addition, Davie, et.al (2013) emphasized the importance of hazard mitigation strategies for schools to focus the needs of children and youth at the period of before, during and after the disaster in considering emergency management in broader sustainability perspectives. Moreover, Muttarak \& Lutz, (2014) showed the importance of academic research that are carried out in a number of geographical, socio-economic, cultural and risk settings which provides clear and reliable evidence of the positive effect of real schooling on impact in disaster assessment.

As such, highly educated citizens and personalities were being documented to practice better preparedness and responsiveness to natural hazards, to suffer fewer losses, and to recover more quickly from such hazards (Muttarak and Lutz, 2014). These studies were also supported by Pantino, et.al (2015) that considered education as a sustainable factor in DRRM and it involves the children and the youth who were considered to be among the most susceptible in times of natural disasters.

Internationally, school disaster education is considered to be important to raise knowledge and awareness between learners and the communities and, most importantly, to encourage preparedness action (Back et al., 2009; Friedman, Rose, \&Koskan, 2011; Jimerson, Brock, \&Pletcher, 2005; Ronan et al., 2012).Parmenter (2012), reflecting on the involvement of schools in Miyagi and Fukushima in 2011 postdisaster Japan, outlined two topics of concern to this essay: the involvement of educators in saving people's lives and guiding societies; and the involvement of teachers as community forums and agents and people in catastrophic events. Current literature on susceptibility and emergency planning typically considers learning as a predictor of social and economic condition, including learning as one element of the susceptibility measure (Kuhlicke et al. 2011).

It was also found out in the study of Dunlop in 2011 that those academic institutions that participated in community disaster response, have increased community resilience and helped achieve specific dimensions of greater preparedness and responses. More studies established that pre-disaster planning can save lives, reduce injury, minimize destruction of property, and minimize disruptions, enabling communities to recover more quickly (MCEER, 2000). It is through education and knowledge therefore that community is able to minimize the suffering and losses caused by earthquakes, (Shaw, Kobayashi, and Kobayashi, 2004).

Formal education has been shown to encourage readiness practices since learning can affect 
cognitive factors and form the interpretation and evaluation of threats, as well as manage danger data (Menard, et al, 2011). This also revealed which trained people may be more conscious of threats because they are more likely to have higher exposure to areas of information and are much more able to assess the data gathered (Jamison and Moock 1984, Rogers 1995, Asfaw and Admassie 2004). Then there was evidence that training improves the development of basic understanding which might affect beliefs, goals, strategic planning capability, and enhance service provision (Thomas et al, 1991;Glewwe, 1999;Burchi, 2010).

Furthermore, students that were adequately equipped with an actual crisis concerning a participant or personnel employee and have adequate catastrophe hazard mitigation services are more likely to be equipped for complicated incidents such as society and environmental disasters (American Academy of Pediatrics, 2008). According to the American Academy of Pediatrics (2008), in regards to the contingency plans, the readiness of the school crisis management plan will maximize the ability of a society to protect the protection of its student population in the case of a school-based or greater society emergency.

It is also reinforced by the study of Vanaspongse, et.al (2007) that the involvement of school systems in children's preparation to face disasters was important. Similarly, Peek (2008), suggested that to reduce children's vulnerability they should be provided with information and resources, participation in climate change mitigation and adaptation activities was needed and individual and community resources must be available. Therefore, the involvement of youngsters in climate change adaptation not just to enhances their awareness and preparedness, and moreover provides the society as a whole through incentives. Only at local level, DRR programs were very well known as a way to minimize susceptibility to all dangers (Mercer, 2010) and can include strong approaches such as investing in infrastructure with certain requirements or soft alternatives, such as awareness and training gathering, for example.

To resolve the issue, Back et al. (2009) suggested that investing in child-centered disaster risk reduction is important because learning and practicing disaster risk reduction while young embeds changed behavior that can be integrated into adult life. Thus, school as avenue of knowledge and information plays great part in disaster preparation. The disaster risk information may then be communicated to the family members and friends of the learners (Ronan et al., 2008; Wisner, 2006). Moreover, the education system as the most productive form of effective communication could relay the knowledge of disaster preparedness in any vulnerable population and it is considered as the quickest means to attain acceptable results in disaster risk reduction (Coburn and Spence, 2006).

It has been confirmed through previous research that school training was among the strongest educational programsto improve earthquake disaster awareness and preparedness in communities, especially when disaster education programs were integrated into school curricula at all levels (Izadkhah and Hosseini, 2005. The purpose of education is indeed a vital one in educating people to meet emergencies.Peek (2008) suggested that children's vulnerability is reduced when they are provided with information and resources and participation in preventing and responding emergency is facilitated and individual and community resources become accessible. Involvement of kids in catastrophe risk mitigation not only builds their resilience to disaster but can also provide benefits for the community as a whole. Research indicated that children were among the most vulnerable individuals to natural disasters (Wisner,Blaike, Cannon, \& Davis, 2004). In addition, kids and young mostly suffer significantly from the catastrophic effects of disasters (Peek, 2008).

Consequently, catastrophe happens as a consequence of human behavior, not necessarily natural processes (Helmer \& Hilhorst, 2006).It can be mitigated and prevented if local communities are able to work with development partners, identify and address it well using local knowledge (Van Aalst et. al, 2008; Mercer et al, 2009) and successful handling of disasters requires the contribution of various parties that have the relevant skills and capabilities in areas such as distribution, engineering, health, security, and others (Hunt, 2008). Therefore, collaboration of different related agencies is encouraged to work together for disaster preparation. 
It seems to be well known that throughout the event of a catastrophe, kids are the most vulnerable group with an estimated 66.5 million students per year by the end of the twentieth century (Penrose and Takaki, 2006). This is because children are very dependent on adults most especially in times of disaster. So therefore, if adults are not able to transfer knowledge and information about disaster preparation, children may not be aware and could not save their lives because they lack preparation to prepare for disaster.Failure to train the youth ensures that kids were likely to suffer a larger number of victims. This is where school could play an important role in educating children about disaster preparedness. There is evidence that cultural misconceptions, as well as incorrect beliefs and attitudes, may lead to inadequate behaviors when preparing for or responding tosuddenly occurring disasters (Alexander, 2007).

Catastrophe training has indeed been recognized as a key path to creating catastrophe communities, apart from real schooling (UNISDR, 2007). There has been proof that emergency awareness programs could have an effect on increasing understanding and knowledge of emergencies, which in turn could stimulate hazard mitigation initiatives (Faupel and Styles 1993; Tanaka, 2005; Page et. al, 2008).In a practical or realistic scenario, the implementation of basic elements of emergency management training must be learned, just like other abilities (Kuntz et. al, 2008).

The coordination and collaboration of all organizations, agencies and stakeholders that could respond to disaster was given emphasis on the study of (Newport and Jawahar,2003). They emphasized the involvement of the group in contingency preparation, community readiness, response team, and processes of response. They argue that without the involvement of vulnerable people and associated formally or informally organizations, risk mitigation would have little impact.Since these, population development approaches have become more popular as the development community understands the advantages of this strategy (Uitto and Shaw, 2006), as local people are able to collaborate with capacity building and recognize threats together, leveraging local expertise to resolve deficiency concerns.

As disaster risk reduction must begin with education, in higher education, universities can play an essential role in educating vulnerable communities about these risks and may influence community attitudes toward earthquake hazards as well as improve community members' preparedness and survival skills (Shaw, Kobayashi, Shiwaku, and Kobayashi, 2004). In research literature which shows that emergency management levels between children and young adults are often low, even in high density areas, this is of key significance (e.g., Paton \& Johnston, 2001; Peek \&Mileti, 2002; Whitney, Lindell, \& Nguyen, 2004).

In 2003, Ronan and Johnston performed a research in Auckland, New Zealand using a relatively non approach that showed that risk education initiatives contributed to improvements in awareness, readiness, and psychological readiness measures.

In addition, Quarantelli, et.al (1998), defined disasters that are events that resulted to severe loss of human life, destruction and suffering. Likewise, Fothergill, et.al (2004),also viewed disasters that caused significant hardship, damage and loss of life especially for the learners who always at school. That effect of a catastrophe relies not just on the form of catastrophe itself, but also with the visibility and distress of the citizens, students and populations affected.With all of these immense tragedies, several reports have shown that at the end of the 20th century, an estimated 66.5 million children were harmed by tragedies annually.This figure was predicted to triple over the second decade of the 21 st century, with up to 175 million children impacted annually by global warming crises (Save the Children, 2008). In this regard, the value of hazard mitigation training in any school is important for alleviating and preventing the tremendous impact of disasters that may affect students, education staff, buildings and as well as the resources.

In the study of Ronan and Johnston (1999) findings revealed that some children have even experienced problems during disaster. But considering their concerns about emergencies, learners can be encouraged to plan for and respond to emergencies through a variety of means, including school-based disaster training programs (Back, Cameron, \& Tanner, 2009; Ronan, Crelin, \& Johnston, 2012).Disasters 
disturb children's daily lives, leading to school disruptions, poor academic progress and potentially destructive behaviors such as violence, liquor and substance Addiction (Silverman and Greca, 2002). Studies that have been conducted in a number of geographical, socio-economic, cultural and danger settings provide clear and reliable proof of the beneficial impact that formal schooling could have on mitigating the impact (Muttarak and Lutz, 2014).

Furthermore, Guevarra, et.al (2007) made a study entitled "Assessment of Disaster Preparedness in Selected Public Schools in Luzon, Philippines", that wanted to determine the status ofdisaster preparedness of selected schools. It also sought to determine the school's preparedness plan and awareness of key school personnel on disaster preparedness programs and DepEd disaster related policies. It is found out in his study that $95 \%$ have formed disaster committees but only $30 \%$ of the respondent from public elementary schools had disaster preparedness plans. $95 \%$ of primary employees in public schools were knowledgeable of locally and nationally disaster response systems, not all participants were aware of DepEd catastrophe strategies nationwide.

More, in Bicol region, Balderas (2013) determined constraints/problems encountered by teachers and principals in DRR implementation. The following problems that were being encountered and found out were as follows: problem on time allotment and lack of DRR learning materials given to teachers and students; overlapping of school activities and hectic work schedules of teachers; and negative attitude of teachers towards DRR.

Moreover, a community research entitled 'Strategic Approach to Managing Risk and Vulnerability to Global Hazards through Experiences Learned: Retooling the Skills of the Iligan City School Superintendent' was conducted by Baculio (2013). It is found out that school administrators were very capable in terms of doing their interpersonal, informational, and decisional roles in managing disaster. Yet, it was discovered that almost all schools have no emergency preparedness program, and the biggest challenge faced by the school officials during the crisis was their students' coping skills over the failure of their families, their management and risk, and their emergency response abilities. Another local researched was showed by Napere (2013) found out that all public schools have emergency/survival kit and eight schools have evacuation plan, DRRM Plan and alarm system. $88.5 \%$ of the teachers did not have trainings related to DRRM while $100 \%$ of the school heads or principal have attended DRRM trainings. In general, $49.67 \%$ of the pupils have knowledge about the different disasters that happened in Iligan City. The teachers generally assessed their level of capability in managing disasters as capable while the compliance of the school heads on DRRM resulted with a moderate degree. Such similar books and journals will definitely be deemed appropriate for the research since they are really related to the issue posted. In addition, they provide direct guidance to help the topic under investigation and to conceptualize it.

In the same token,Mateo and Oki, (2011) which indicated that the Philippines is situated in the Pacific tropical zone, which often experiences heavy precipitation. On the other hand, During November 68, 2013, a strong storm and storm surge triggered by Super Typhoon Haiyan attacked the central region (Visayas). The typhoon affected Leyte and Samar mainly (Daniell et al., 2013).In other words, Leelawat et al. (2014) argued that TV in any duration of time would be the most common way for authorities to disclose catastrophe alert (i.e., 1 week prior, a few days before, and just prior impact). However, as the typhoon progressed, the TV score decreased, while the radio preference increased as its effect contacted. Whereas the majority of individuals obtained a warning message, $47 \%$ did not abandon to housings.

In addition, Leelawat, Mateo, Gaspay, Suppasri, and Imamura (2014), who reported that there are various stages of knowledge among students in different places. They also mentioned that students considering catastrophes in a school near the sea are dreadfully stronger than schools far from the coast, perhaps because their position would be along the coastline. They also claimed that students schooling on 
the hilly areas, where at that time the disaster occurred, have greater knowledge of the near future hazards than students who went to school on level field. Furthermore, learners that are deemed to be environmental events by their school on the hill are dreadfully higher than flat area school learners. Better knowledge and comprehension of flood management was effective in promoting the enhancement of emergency preparedness mitigation. In addition, Bollettino, Alcayna, Enriquez, and Vinck (2018) claimed that the Filipino disaster preparedness, planning, coping and adaptation revealed that on the national average, Filipinos were divided by 31 per cent and said that they were only marginally ready or not at all willing to react to a catastrophe in the coming days.

\section{METHODOLOGY}

The study used quantitative-qualitative method of research to appraise the flood preparedness of the eight (8) selected schools of Zamboanga del Sur and Zamboanga Sibugay in terms of school disaster risk reduction group, disaster risk reduction plan, disaster risk reduction measures; capabilities of teachers on flood preparedness and mitigation, flood response, flood rehabilitation and; the orientation of pupils on flood in the school; and the availability of DRRM materials. Purposive and random sampling were employed to get the number of the respondents from the population. The study used researcher-made questionnaires that went through series of tests to check its validity and reliability. The first set of questionnaire has a reliability of .916 Cronbach Alpha, while the questionnaire for teachers has .809 Cronbach Alpha and questionnaire for the pupils has a Cronbach Alpha of .952.

The research also employed focus group discussion and in-depth interviews to deepen the collection of data from the Municipal Local Disaster Risk Reduction evaluators of each municipality, from the teachers and the pupils.

\section{PRESENTATION AND INTERPRETATION OF RESULTS}

Table 1. Flood Preparedness of the Eight Selected Elementary Schools of Zamboanga del Sur and Zambonga Sibugay

\begin{tabular}{lccc}
\hline \multicolumn{1}{c}{ Level of Preparedness } & $\begin{array}{c}\text { School Disaster } \\
\text { Risk Reduction } \\
\text { Group } \\
\text { Organization }\end{array}$ & $\begin{array}{c}\text { School Disaster } \\
\text { Risk Reduction } \\
\text { Plan Preparation }\end{array}$ & $\begin{array}{c}\text { Disaster Risk } \\
\text { Reduction } \\
\text { Measure } \\
\text { Implementation }\end{array}$ \\
\hline Outstanding & 0 & 0 & 0 \\
Very Satisfactory & 0 & 0 & 0 \\
Satisfactory & 0 & 0 & 0 \\
Very Good & 1 & 3 & 1 \\
Good & 7 & 5 & 7 \\
Needs Improvement & 0 & 0 & 0 \\
(N=8) & & & \\
\hline
\end{tabular}

As depicted in Table 1, there are three unquestionable factors that need to be considered by the schools to be prepared in flood. These are School Disaster Risk Reduction Group (SDRRG) organization, School Disaster Risk Reduction Plan (SDRRP) preparation, and implementation of disaster risk reduction measures (DRRMs). The outcome indicates that only one school was able to organize their SDRRG and implement their SDRR Measures. Therefore, only one school rated very good on the level of flood preparedness. The SDRRG of the school was represented by their internal and external stakeholders and 
with the different sectors in the community. The organizational set-up of their SDRRG is well organized because the qualities, training and expertise of the leaders and members undergone assessment and each of them know and understand their roles and functions because it was clearly defined for them. This is reinforced by Newport and Jawahar (2003) emphasizing the importance of coordination and collaboration of all organizations, agencies and stakeholders that would respond to disaster by underscoring community engagement in emergency preparation, public readiness, working group and control measures. Uitto and Shaw (2006) also backed-up this result by mentioning that any contingency plan would have little impact if there is no involvement of the vulnerable populations which is associated to explicit or implicit organizations, therefore the linkage between and among organizations appears to be common to take place in a community for development. On the other hand, the school was also able to implement SDRR Measures by following the guidelines set by their Local Government Disaster Risk Reduction Management Office on preparedness and mitigation (before), response (during) and, relief and rehabilitation (after), also through identifying the exits and evacuation sites known to the school community and by establishing agreement with the other agencies for assistance during disaster. It was also found out in the study of Dunlop in 2011 that those academic institutions that participated in community disaster response, have increased community resilience and helped achieve specific dimensions of greater preparedness and responses. It is through education and knowledge therefore that community is able to minimize the suffering and losses caused by earthquakes, (Shaw, Kobayashi, and Kobayashi, 2004).

Furthermore, the result also implies that three schools were able to prepare the SDRR Plan by conducting flood vulnerability and susceptibility survey, assessing the condition of the school buildings, involving the teachers, community and other stakeholders in the preparation of School DRR plan and assessing the needs of the community in planning for training in DRR. Davie, et.al (2013) emphasized the importance of hazard mitigation strategies for schools to focus the needs of children and youth at the period of before, during and after the disaster in considering emergency management in broader sustainability perspectives. More studies also established that pre-disaster planning can save lives, reduce injury, minimize destruction of property, and minimize disruptions, enabling communities to recover more quickly (MCEER, 2000).

Table 2. Teachers' Capability on Addressing Flood in their School

\begin{tabular}{|c|c|c|c|c|c|c|}
\hline \multirow{2}{*}{ Level of Capability } & \multicolumn{2}{|c|}{$\begin{array}{c}\text { Flood } \\
\text { Preparedness } \\
\text { and } \\
\text { Mitigation }\end{array}$} & \multicolumn{2}{|c|}{ Flood Response } & \multicolumn{2}{|c|}{ Flood Rehabilitation } \\
\hline & Frequency & Percentage & Frequency & Percentage & Frequency & Percentage \\
\hline Very Capable & 93 & 76.7 & 104 & 86.0 & 97 & 80.2 \\
\hline Capable & 26 & 21.6 & 13 & 10.7 & 16 & 13.2 \\
\hline $\begin{array}{l}\text { Neither capable nor } \\
\text { incapable }\end{array}$ & 2 & 1.7 & 4 & 3.3 & 5 & 4.1 \\
\hline Incapable & 0 & 0 & 0 & 0 & 0 & 0 \\
\hline $\begin{array}{l}\text { Very Incapable } \\
(\mathrm{N}=121)\end{array}$ & 0 & 0 & 0 & 0 & 0 & 0 \\
\hline
\end{tabular}

The table presents the responses of the 121 teacher-respondents which yielded the following results: 93 respondents are very capable in flood preparedness and mitigation, 104 teacher-respondents are very capable in flood response and 97 of the respondents are very capable in flood rehabilitation. This infers that majority of the teachers are always ready to address and act before, during and after the flooding in their school. This is in response to the second goal of the Hyogo Framework of Action (HFA) which is to 
understand the consequences and take appropriate steps through early warning and by recognizing, evaluating and tracking disaster risk. Moreover, majority of the teachers also responded priority 3 of HFA that suggest building understanding and awareness that resulted from information dissemination, advocacy and campaign about the localized disaster in the community which increases the understanding and awareness of every individual. As an end, this leads to attain Priority 4 of the said framework which is reducing the risk of the localized disaster towards the community. In addition, according to the American Academy of Pediatrics (2008), in regards to the contingency plans, the readiness of the school crisis management plan will maximize the ability of a society to protect the safety of its student population in the case of a school-based or greater society emergency. Furthermore, Parmenter (2012), pointed the major function of educators in ensuring safety and guiding school community and the importance of education in crisis situations as places and members of culture and community.

Table 3. Pupils' Orientation of Flood in the Eight Selected Elementary Schools

\begin{tabular}{lcl}
\hline \multicolumn{1}{c}{ Level of Orientation } & Frequency & Percentage \\
\hline Fully Informed & 27 & 28.4 \\
Almost Fully Informed & 35 & 36.9 \\
Partially Informed & 29 & 30.5 \\
Slightly Informed & 4 & 4.2 \\
Never Informed & 0 & 0 \\
$\mathbf{( N = 9 5 )}$ & &
\end{tabular}

Table 3 reflected the level of pupils' orientation on flood on their respective schools. As exhibited, there are 35 or 36.9 per cent of the pupils who are almost fully informed. This is seconded by the 29 or 30.5 per cent of the pupils who considered themselves partially informed and followed by 27 or $28.4 \%$ who are fully informed. Majority of the information that are common among the three groups are the following: where in their school campus flood water may enter during heavy rainfall, whom to call when flood water enters their school, where is the safe place to go when flood water enters the school, how to do it as well during the flood, where the school's corridors and other escapes are when the floods occur, where is the identified evacuation sites in their community, what are the flood warning system, to watch out fast rising flood water, Ingest only well-cooked foods only clean drinking water during disaster. To keep away with any structure which is still submerged, the degree of vulnerability of the campus to floods, the reasons of school flooding, never to cross on flowing rivers and listen continuously to local radio station for updated information.

It is also very well known that kids are perhaps the most vulnerable group mostly in event of a catastrophe and will continue to damage an approximate 66.5 million students per year by the end of the twentieth century (Penrose and Takaki, 2006). This could be because children were very dependent on adults most especially in times of disaster. So therefore, if adults were not able to transfer knowledge and information about disaster preparation, children may not be aware and could not save their lives because they lack preparation to prepare for disaster. Inability to educate young people implies that more victims and accidents between kids could be anticipated. This was how school plays the important role in educating children about disaster preparedness.

The study by Vanaspongse, et.al (2007) also reinforced the role and importance of education in educating people for crises. Similarly, Peek (2008), suggested that to reduce children's vulnerability they should be provided with information and resources, participation in climate change mitigation and adaptation programs was required and should have access to government and community resources. Thus, kid's involvement in catastrophe risk mitigation not only strengthens their awareness and preparedness, but also supports the society as a whole. DRR operations were well known at community level as a means of 
minimizing susceptibility to all dangers (Mercer, 2010) and can include "extreme interventions" such as building facilities to certain requirements or easy alternatives, such as awareness and training.

In addition, principals and teachers should show fearlessness and trust in the event of a tragedy, even though this was not what they experienced. Educational institutions should concentrate on the wellbeing of learners, workers and parents, and on bringing kids back to healthy learning habits when addressing continuing distress (Education Review Office, 2013). Furthermore, Boon (2014) stressed that school disaster education was essential to raise awareness among learners and their communities and to encourage preparedness action. Lack of knowledge about disasters among the people and lack of provision of mitigation measures could be a reason for millions of people and millions of dollars' worth of damage to properties and lots of people die and others could be homeless, and this also has a detrimental impact mostly on community's public development.

It has been confirmed through previous research that school training was among the strongest educational programs to improve earthquake disaster awareness and preparedness in communities, especially when disaster education programs were integrated into school curricula at all levels (Izadkhah and Hosseini, 2005).

Furthermore, students that were adequately equipped with an actual crisis concerning a participant or personnel employee and have adequate catastrophe hazard mitigation services are more likely to be equipped for complicated incidents such as society and environmental disasters(American Academy of Pediatrics, 2008). According to the American Academy of Pediatrics (2008), in regards to the contingency plans, the readiness of the school crisis management plan will maximize the ability of a society to protect the safety of its student population in the case of a school-based or greater society emergency.

Table 4.Availability of Disaster Risk Reduction Management Materials/ Equipment/ Facilities

\begin{tabular}{cllc}
\hline $\begin{array}{l}\text { DRRM Materials/Equipment/Facilities } \\
(\mathrm{N}=8)\end{array}$ & Available & Not Available \\
\hline 1. & Emergency/Survival Kit & 6 & 2 \\
2. & Evacuation Plan in Every Building & 4 & 4 \\
3. & Disaster Risk Reduction Plan & 8 & 0 \\
4. & Siren/Bell & 8 & 0 \\
5. & Drainage System & 4 & 4 \\
6. & Flood Early Warning System & 6 & 2 \\
7. & Emergency Alarm & 6 & 2 \\
8. $\quad$ Fire Extinguisher & Evacuation Site & 3 & 2 \\
9. & Rope and Life Vest & 3 & 0 \\
10. & & 5 & 5
\end{tabular}

Table 4 presents the number of schools that have Disaster Risk Reduction Management materials, equipment and facilities. The result depicts that most of the schools have emergency /survival kit, evacuation plan in every building, disaster risk reduction plan, siren/bell, drainage system flood early warning system, emergency alarm, fire extinguisher, evacuation site and, rope and life vest that are important where flood occurs in the school. The availability of the DRRM related materials in the school is an indication that the school administrator is concern on the safety of the lives of every individual inside the school society. The said materials also protect the school properties and the school itself from damages. The result of this study is 
the same with the result of the study of Napere (2013) which found out those public schools in Iligan City, Philippines have emergency/survival kit, evacuation plan, DRRM plan and alarm system. Pillar 1 of Comprehensive School Safety suggested the safety of learning facilities which entails education and planning authorities who are decision makers to select safe school site, design, construct and maintain the schools to make learning environment and facilities safe for the learners and education workers.

\section{CONCLUSION AND RECOMMENDATION}

The rating on the level of organization of School Disaster Risk Reduction Group, preparation of the Disaster Risk Reduction Plan and the implementation of Disaster Risk Reduction Measures made the eight selected elementary schools of Zamboanga del Sur and Zamboanag Sibugay withstand flood and have developed resiliency among the school population. It also inferred that most of the teachers are always all the time prepared to do activities and emergency approaches before, during and after flooding in their school. Furthermore, pupils are well-informed about flooding in their school thus, their highest level of orientation made them prepared always. Lastly, the selected eight elementary schools have not yet completed the needed materials relative to Disaster Risk Reduction Management.

It is suggested that the organization of School Disaster Risk Reduction Group, the preparation of the School Disaster Risk Reduction Plan and, the execution of the Disaster Risk Reduction Measures must be at all costs complied completely and be fully implemented to the highest level by the schools as these will be the backbone of the school community in disaster preparedness and an essential tools for the school community to cope up with disaster to be a school-resilient community.

Moreover, it is recommended for the teachers to enhance their capabilities not only on flood but also to fire, earthquake, typhoon, and landslides and other local hazards. It is also highly recommended that teachers should engage themselves on training for Basic Life Support every year for refreshment.

In addition, it is also recommended that students regularly refresh their awareness and insight of local hazards so that they can always practice appropriate steps and preparedness. They are also encouraged to read brochure about local hazards made and given by their Local Disaster Risk Reduction and Management Office.

It is recommended for the LDRRMO to evaluate quarterly the schools if they are compliant to the guidelines and requirements given by their office. It is recommended that the results of the assessment must be presented specifically in order for the concerned school to take effective action. Schools that complied and implemented the guidelines given by the LDRRMO must be given credit or award by the Local Government Unit. It is also suggested that the LDRRMO would circulate local disaster brochures, flyers and publications to increase students' awareness and understanding.

Lastly, planning and organizing the school DRR plan, the Barangay local government unit can cooperate with the educational institutions. The Barangay local government unit must give financial support to schools in purchasing disaster risk reduction materials and equipment's and for the development of infrastructure for disaster risk mitigation.

\section{REFERENCES}

AAP. (2008). American Academy of Pediatrics . National Conference and Exhibition.

Asfaw, A., \& Admassie, A. (2004). The role of education onthe adoption of chemical fertiliser under differentsocioeconomic environments in Ethiopia. AgriculturalEconomics, 30, 215-228. 
Back, E., Cameron, C., \& Tanner, T. (2009). Children and disaster risk reduction: Taking stock and moving forward (Children in a Changing Climate Coalition Research Paper). Brighton, UK: Institute of Development Studies.

Boon, H., \& Pagliano, P. (2015). Disaster Education in Australian Schools. Australian Journal of Environmental Education, 30(02), 187-197.

Burchi, F. (2010). Child nutrition in Mozambique in 2003: therole of mother's schooling and nutrition knowledge. Economics and Human Biology , 8, 331-345. Retrieved from http://dx.doi/org/10.1016/j.ehb.2010.05.010

Davie, S. (2013). Don't leave me alone. Protecting children in Australian disasters and emergencies:Government report card on emergency managementplanning. Melbourne, Australia: Save the Children. Retrieved from http://www.savethechildren.org.au/

Dunlop, A. L. (2011). Role of academic institutions in community disasterresponse since September 11, 2001. Disaster Medicine and Public Health Preparedness, 5(3), 218.

Department Order No. 55. (2007). Prioritizing the Mainstreaming of the Disaster Risk Reduction Management to the school system and implementation of the programs and projects relative therefore.

Department Order No. 21. (2015). Disaster Risk Reduction and Management Coordination and Information Management Protocol

Education Review Office. (2013). Stories of resilience and innovation in schools and early childhood services. Canter bury earthquakes: 2010-2012. Wellington, New Zealand.

Friedman, D., Rose, I., \& Koskan, A. (2011). Pilot assessment of an experientialdisaster communication curriculum. Disaster Prevention and Management, 20, 238-250.

GADRRRES. (2017). Global Alliance for Disaster Risk Reduction and Resilience in Education Sector.

Glewwe, P. (1999). Why does mother's schooling raise childhealth in developing countries? Evidence from Morocco. Journal of Human Resources 3:124-159. Retrieved from http://dx.doi/org/10.2307/146305

Hyogo Framework. (2005). Hyogo framework for action 2005-2015: Building theresilience of nations and communities to disasters. Paper presented at WorldConference on Disaster Reduction, 18-22 January, Hyogo, Japan.

Izadkhah, Y., \& Hosseini, M. (2005). Towards Resilient Communities Developing Countries Through Education of Children for Disaster Preparedness. International Journal for Emergency Management. Retrieved from http://www.environmental-expert.com/

Jamison, D. T., \& Moock., P. R. (1984). Farmer education andfarm efficiency in Nepal: the role of schooling, extensionservices, and cognitive skills. World Development, 12, 67-86.

Jimerson, S., Brock, S., \& Pletcher, S. W. (2005). An Integrated Model of School Crisis Preparedness and Intervention: A Shared Foundation to Facilitate International Crisis Intervention. School Psychology International, 26(3), 275-296. Retrieved from https://www.researchgate.net/deref/http\%3A\%2F\%2Fdx.doi.org\%2F10.1177\%2F01430343050559 74

Kuntz, J. C., Malinen, S., \& Näswall, K. (2017). Employee resilience: Directions for resilience development. Consulting Psychology Journal, 69(3), 223-242.

Kuhlicke, C., Steinfuehrer, A., Begg, C., Bianchizza, C., \& Bruendl, M. (2011). Perspectives on social capacity building for natural hazards: outlining an emerging field of research and practice in Europe. Environmental Science and Policy. 2011, 14(7), pp. 804-814.

MCEER. (2000). Multidisciplinary Center for Earthquake Engineering Research. Strategic plan 2000.

Menard, Slater, R., \& Flaitz, J. (2011). Disaster preparedness and educational attainment. Journal of Emergency 
doi:https://www.researchgate.net/deref/http\%3A\%2F\%2Fdx.doi.org\%2F10.5055\%2Fjem.2011.006 6

Mercer, J. (2010). Disaster risk reduction or climate change adaptation: Are we reinventing the wheel? Journal International Development. Retrieved from https://doi.org/10.1002/jid.1677

Mills, J., West, C., Langtree, T., Usher, K., Henry, R., Chamberlain-Salaun, J., \& Mason, M. ( 2014.). Putting it together': unfolding case studies and high fidelity simulation in the first-year of an undergraduate nursing curriculum. Nurse Educ. Pract., 14 (1), 12-17.

Muttarak, R., \& Lutz, W. .. (2014). Is education a key to reducing vulnerabilty tonatural disasters and hence unavoidable climate change?,. Ecology and Society Office., 19(1), 42-52.

Napere. (2013). Characterization of the School System on Disaster Risk Reduction and Management (DRRM) of Public Central Schools in Iligan City, Philippines.

Newport, J., \& Jawahar, G. (2003). Community participation and public awareness in disaster mitigation.

Disaster Prevention and Management, 12 (1), 33-6

Pantino, J. (2015). Knowledge is Power: A Policy Proposal about the Integration of Disaster Risk Reduction and Management Principles in the Elementary, Secondary and Tertiary Education in the Philippines. Education Philippine Disaster Management Sustainability and Public Policy.

Parmenter, L. (2012). Community and citizenship in post-disaster Japan: The roles of schools and students. Journal of Social Science Education, 11(3), 6-21.

Peek, L. (2008). Children and disasters: Understanding vulnerability, developing capacities and promoting resilience-an introduction. Children, Youth andEnvironments, 18, 129.

Penrose, A., \& Takaki, M. (2006). Children's rights in emergencies and disasters”,. The Lancet, 367 ( 9511 ), 698-699.

RepublicAct No10121. (2010). Philippine Disaster Risk Reduction and Management Act.

Rogers, E. M. ( 1995). Diffusion of innovations. Fourth edition. Free Press, New York, New York, USA. .

Shaw, R., Kobayashi, K., Shiwaku, H., \& Kobayashi, M. (2004). Linking experienceeducation, perception and earthquake preparedness. Disaster Preventionand Management, 13(1), 39-49.

Thomas, D., Strauss, J., \& Henriques, M. (1991). How doesmother's education affect child height? Journal of HumanResources , 26, 183-211. Retrieved from http://dx.doi.org/10.2307/145920

Uitto, J., \& Shaw, R. (2006). Adaptation to Changing Climate: Promoting Community-based Approaches in the Developing Countries. International Journal of Disaster Risk Management (IJDRM). Retrieved from

https://www.researchgate.net/publication/42251186_Adaptation_to_Changing_Climate_Promoting _Community-based_Approaches_in_the_Developing_Countries? ${ }^{-}{ }^{-}$richId $=$rgreq$1561077 \mathrm{cc} 9 \mathrm{f} 8 \mathrm{~b} 225 \mathrm{~b} 8613 \mathrm{a} 17 \mathrm{a} 3 \mathrm{~d} 1 \mathrm{~d} 01 \mathrm{a}-$ XXX\&enrichSource=Y292ZXJQYWdlOzQyMjUxMTg2O0FTOjk3NzEzNzgxNzM5

UNISDR. (2005). World Conference on Disaster Reduction. Kobe, Hyogo, Japan. Retrieved from http://www.unisdr.org/

UNISDR. (2015). The United Nations Office for Disaster Risk Reduction (UNISDR Towards a Post - 2015 Structure for Disaster Risk Reduction) .

Uitto, J., \& Shaw, R. (2006). Adaptation to Changing Climate: Promoting Community-based Approaches in the Developing Countries. International Journal of Disaster Risk Management (IJDRM). Retrieved from

https://www.researchgate.net/publication/42251186_Adaptation_to_Changing_Climate_Promoting _Community-based_Approaches_in_the_Developing_Countries? $\overline{\text { enrichId }}=$ rgreq-

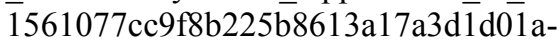
XXX\&enrichSource=Y292ZXJQYWdlOzQyMjUxMTg2O0FTOjk3NzEzNzgxNzM5 
Vanaspongse, C., Ratanachena, S., Rattanapan, J., Chutong, S., \& Intraraksa, R. (2007). Training manual child-led disaster risk reduction in schools and communities.Bangkok: Save the Children SwedenSoutheast Asia and ThePacific Regional. 